\title{
Comparative Assessment of Corrosion Behaviour of MCS and KS7 SS in Saline and Carbonate Environments
}

\author{
Olusegun Olufemi Ajide*, Kamorudeen Wemimo Agara \\ Department of Mechanical Engineering, University of Ibadan, Ibadan, Nigeria \\ Email: "getjidefem2@yahoo.co.uk
}

Received June 8, 2012; revised July 19, 2012; accepted August 10, 2012

\begin{abstract}
The major objective of this experimental study is to investigate and compare the corrosion resistance of medium Carbon steel (MCS) and KS7 stainless steel in saline and sodium carbonate environments. The MCS and KS7 SS were exposed to $0.5 \mathrm{M}$ each of $\mathrm{NaCl}$ and $\mathrm{Na}_{2} \mathrm{CO}_{3}$ solutions for a period of 36 days. The weight loss was taken every 3 days in order to evaluate CPR. The results obtained showed that KS7 SS generally offers a better corrosion resistance than the MCS in the selected media. While MCS is found to be inappropriate alloy in saline and sodium carbonate environments, KS7 SS is an unfailing choice material for manufacturing machines and other engineering amenities in which their service lives are predominant in $\mathrm{Na}_{2} \mathrm{CO}_{3}$ medium and fairly pleasing in $\mathrm{NaCl}$ environment.
\end{abstract}

Keywords: MCS; KS7 SS; CPR; Saline and Sodium Carbonate

\section{Introduction}

The challenges of corrosion in manufacturing and domestic sectors are enormous. Corrosion is the major problem facing exploration, production and processing in oil and gas, food and construction industries. It is therefore germane to concentrate efforts and resources towards meaningful researches that will be a relief to the numerous harms of corrosion in industries. [1] studied the Corrosion behaviour of dc magnetron sputtered $\mathrm{Fe}_{1-x} \mathrm{Mg}_{x}$ alloy films in $3 \mathrm{wt} \% \mathrm{NaCl}$ solution. $\mathrm{Fe}_{1-x} \mathrm{Mg}_{x}$ alloy films (with $x \leq 43.4$ at $\% \mathrm{Mg}$ ) were deposited by de magnetron sputtering onto glass slide substrates. The aim of their work was to characterize the corrosion properties of these alloys in saline solution for application as new friendly environmentally sacrificial coatings in the protection of steel structures. The morphological and structural properties of the alloys were systematically studied prior to electrochemical experiments, and then the degraded surfaces were analyzed to determine the composition and nature of corrosion products. The reactivity of the alloys in saline solution is strongly dependent on the $\mathrm{Mg}$ content and the alloy structure. A transition in corrosion activity is observed at $25 \% \mathrm{Mg}$ from which the reactivity decreases with the magnesium content increase. From this paper, it is evident that an increase in $\% \mathrm{Mg}$ decreases the corrosion rates of this alloy. [2] presented a paper on corrosion assessment of offshore oil pipeline based on ultrasonic technique. He developed an intelli-

\footnotetext{
"Corresponding author.
}

gent ultrasonic inspection device for offshore pipeline inspection and software for corrosion assessment of offshore pipeline. [3] in 2009 work studied the comparative corrosion behaviour of $\mathrm{Al} 3103$ and galvanized steel roofing sheets in $1 \mathrm{M}, 0.5 \mathrm{M}$ and $0.3 \mathrm{M}$ solutions of sodium carbonate and sodium chloride. Samples of the aluminium and galvanized sheets were subjected to the different environments for thirty days. The electrode potentials, in $\mathrm{mV}$ (SCE), were measured every day. Electrode potential measurements were taken every day for thirty consecutive days. Weight loss or gain measurements were taken every three days for the duration of the exposure period. The results of their study showed that sodium chloride environment had higher corrosive effect on the galvanized roofing sheet than sodium carbonate environment while the reverse was true for aluminium sheets. Also, galvanized steel roofing corroded more than aluminium roofing in both carbonate and chloride environments. Corrosion of galvanized steel roofing was continuous throughout the exposure period in all the environments used. The conclusions drawn by the authors is that galvanized steel roofing sheet is not a suitable material for roofing in carbonate and chloride environments or in industrial environments where chloride or carbonate contamination is possible. [4] evaluated the corrosion behaviour of carbon steel under stagnant seawater conditions. 1020 carbon steel coupons were subjected to natural seawater for a 1-year period. The study showed that this alloy is more corrosive in anaerobic stagnant seawater conditions than aerobic conditions. The study also 
revealed that in both aerobic and anaerobic exposures, corrosion was more aggressive on horizontally oriented coupons compared to vertically oriented samples. The corrosion behaviour of low carbon steel was investigated in natural seawater and various synthetic seawaters as reported by [5] in 2006. It was found that the steel corroded nearly four times faster in a $3.5 \% \mathrm{NaCl}$ solution than in natural seawater for an exposure time of 21 days. The corrosion rate after immersion in synthetic seawaters (ASTM D1141 and Marine Biological Laboratory seawater) is similar to the corrosion rate after immersion in natural seawater. Calcium carbonate (aragonite) deposits were found on the surface of the steel after immersion in natural seawater and the synthetic seawaters. Some magnesium-containing deposits were also found after immersion in the natural seawater. These deposits act as a barrier against oxygen diffusion and thereby lower the corrosion rate. The morphology of the calcium carbonate deposits that formed during immersion in the natural seawater is different from those formed during immersion in the solution. [6] studied the electrochemical corrosion behaviour of carbon steel X60 using the electrochemical impedance spectroscopy and potentiodynamic polarization methods. $0.5 \mathrm{M}$ test solutions of sodium chloride, sodium sulphate and sulphuric acid were used in a three electrode open cell. The findings of the authors showed that the rate of corrosion penetration is higher for carbon steel X60 in $0.5 \mathrm{M}$ sulphuric acid and smaller in $0.5 \mathrm{M}$ sodium sulphate. [7] studied the corrosion behaviour of steel for snow and rockfall barriers using electrochemical techniques to quantify corrosion rate. His results generally showed that steels have high corrosion rate in these media. Synthetic seawaters. This may explain the slightly lower corrosion rates obtained in the natural seawater. X-ray diffraction also showed that the oxy-hydroxides formed in the $3.5 \% \mathrm{NaCl}$ solution differed from those formed in the other solutions. [8] investigated the corrosion behaviour of carbon steel in alkaline medium in the presence of very low concentration of polymeric nanoaggregates $(0.0024 \mathrm{wt} \%$ polyethylene oxide-PEO-113-b-PS70 micelles). The steel electrodes were investigated in chloride-free and chloride-containing cement extracts. The electrochemical measurements, electrochemical impedance spectroscopy and potentiodynamic polarization indicate that the presence of micelles alters the composition of the surface layer and influences the electrochemical behaviour of the steel. Authors' observation shows that micelles initially improved the corrosion resistance of the steel whereas no significant improvement was observed within longer immersion periods. Surface analysis, performed by environmental scanning electronic microscopy, energy-dispersive X-ray analysis and X-ray photoelectron spectroscopy supports and elucidates the corrosion performance characteristics of carbon steel in simulated pore solution in the presence of Micelles. [9] in 2011 did a comparative study of corrosion resistance between 316 and different duplex stainless steel grades. He examined and compared the corrosion properties of $316 \mathrm{~L}$ austenitic stainless steel and duplex grades of LDX2101, SAF2304, AL2003, LDX2404, 2505 and 2507. The stainless steels were given heat treatment at temperature of $800^{\circ} \mathrm{C}$ for 30 minutes. Influence of heat treatment on pitting susceptibility of stainless steels was estimated using cyclic polarization scan which is based on ASTM standard G150. Metallurgical analysis was conducted to find a correlation between microstructure and pitting resistance. Light microscope was used for the examination of stainless steel microstructure. In addition, test samples were examined virtually after pitting tests and critical pitting test to determine the corrosion form which was present. The results of his research showed that pitting corrosion resistance and critical pitting temperature (CPT) values of heat treated highly alloyed steels were affected adversely compared with the results from non-heat treated materials. The author affirmed that for stainless steel alloys, the results can be attributed to metallurgical aspects such as sigma, chromium nitrides, secondary austenite and etc. The author concluded that the precipitations have significant effects on corrosion behaviour in stainless steel alloys. [10] investigated the influence of $\mathrm{CO}_{2}$ on the corrosion behaviour of $13 \mathrm{Cr}$ martensitic stainless steel AISI 420 and low-alloyed steel AISI 4140 exposed to saline aquifer water environment. In order to guarantee the safety of the site, $\mathrm{CO}_{2}$-corrosion of the injection pipe steels has to be given special attention. To get to know the corrosion behaviour samples of the heat treated steel AISI 4140 , $42 \mathrm{CrMo} 4$, used for casing, and the martensitic stainless injection pipe steel AISI 420, X46Cr13 were kept at $\mathrm{T}=$ $60^{\circ} \mathrm{C}$ and $\mathrm{p}=1-60 \mathrm{bar}$ for $700 \mathrm{~h}-8000 \mathrm{~h}$ in a $\mathrm{CO}_{2}$-saturated synthetic aquifer environment similar to the geological CCS-site at Ketzin, Germany .The isothermal corrosion behaviour obtained by mass gain of the steels in the gas phase, the liquid phase and the intermediate phase gives surface corrosion rates around 0.1 to 0.8 $\mathrm{mm} /$ year. This implies that Severe pit corrosion with pit heights around $4.5 \mathrm{~mm}$ are only located on the AISI 420 steel. Main phase of the continuous complicated multilayered carbonate/oxide structure is siderite $\mathrm{FeCO}_{3}$ in both types of steel. The corrosion of 18-8 stainless steel in sodium chloride solutions was studied by [11]. It was established that under certain conditions, 18-8 stainless steel is likely to fail in contact with sodium chloride solutions through formation of deep pits. 200 series stainless steel is currently of great interest to material researchers, engineers and steel vendors due to its distinctive mechanical characteristics and acceptable corrosion behaviour. According to [12], new grades of the 200 
series have been uncovered for the European market. It is a potential substitute to austenitic grade AISI 304. It has low nickel content without compromising its austenite phase former characteristic. A cautious comparison of the experimental data of the new 200 series and the existing 300 and 400 series stainless steels were made. This article revealed that the new 200 grades have mechanical properties slightly superior to AISI 304 combined with satisfactory corrosion resistance behaviour.

\section{Materials and Methods}

\subsection{Chemical Analysis}

The MCS was procured from the universal steel Limited, Ikeja, Lagos state while KS7 SS was bought from a stainless steel commercial dealer in Nigeria. KS7 SS is one of the 200 series stainless steels produced by KAD Steel Rolling Mills in India. The chemical Composition Analysis of Medium Carbon steel (MCS) and KS7 Stainless steel that was carried out at the Universal steel Limited, Lagos state in Nigeria are shown in Tables 1 and 2 respectively.

\subsection{Weight Loss Measurements}

The MCS and KS7 SS samples were machined into cylindrical and rectangular coupons of $15 \mathrm{~mm}$ diameter and $41 \mathrm{~mm}$ long and $44 \mathrm{~mm}$ by $45 \mathrm{~mm}$ respectively. The cou- pons surfaces were treated by abrading them through successive grades of silicon carbide papers of grades 60 and 120 grit, and finally on the $0.05 \mu \mathrm{m}$ emery cloth grade. They were rinsed in distilled water and then in acetone and later dried. The prepared coupons were stored in desiccators until when used for the experiments. After three days of storage; the coupons were immersed in each $0.5 \mathrm{M}, 100 \mathrm{ml}$ of $\mathrm{NaCl}$ and $\mathrm{Na}_{2} \mathrm{CO}_{3}$ Solutions for a period of 36 days. The corrosion coupons were removed from the corrosion media with the aid of a tong. These were then properly cleaned in distilled water and dried with cotton wool. The dried samples were weighed with the electronic digital weighing balance and recorded. Weight loss measurements of coupons were recorded at interval of 3 days. The corrosion penetration rate (CPR) were evaluated from the weight loss measurements using the Equation (1):

$$
\mathrm{CPR}=\frac{K W}{\rho A t}
$$

where $K=$ constant $=3.45 \times 10^{6}$;

$\mathrm{CPR}=$ Corrosion Penetration Rate in mils per year (mpy);

$W=$ the weight loss in grams;

$A=$ Area of exposed specimen in $\mathrm{cm}^{2}$;

$t=$ time or duration of exposure in hours;

$\rho=$ Density of material in $\mathrm{g} / \mathrm{cm}^{3}$.

Table 1. Chemical composition analysis of medium carbon steel (MCS).

\begin{tabular}{ccccccccccccc}
\hline Run & & $\mathrm{C}$ & \multicolumn{2}{c}{$\mathrm{Si}$} & $\mathrm{S}$ & $\mathrm{P}$ & $\mathrm{Mn}$ & & $\mathrm{Ni}$ & $\mathrm{Cr}$ \\
\hline 1 & & 0.3397 & 0.2191 & 0.0573 & 0.0620 & 0.8294 & 0.0960 & 0.1242 \\
2 & & 0.3426 & 0.2204 & 0.0605 & 0.0597 & 0.8343 & 0.0961 & 0.1245 \\
$\mathrm{Avg}$ & & 0.3411 & 0.2198 & & 0.0589 & 0.0609 & 0.8318 & & 0.0960 & 0.1244 \\
\hline $\mathrm{Mo}$ & $\mathrm{V}$ & $\mathrm{Cu}$ & $\mathrm{W}$ & $\mathrm{As}$ & $\mathrm{Sn}$ & $\mathrm{Co}$ & $\mathrm{Al}$ & $\mathrm{Pb}$ & $\mathrm{Ca}$ & $\mathrm{Zn}$ & $\mathrm{Fe} \%$ \\
\hline 0.0188 & 0.0057 & 0.2066 & 0.0035 & 0.0056 & 0.0252 & 0.0088 & -0.0007 & 0.0001 & 0.0001 & 0.0035 & 97.9951 \\
0.0191 & 0.0058 & 0.2077 & 0.0035 & 0.0059 & 0.0262 & 0.0088 & -0.0007 & -0.0000 & 0.0001 & 0.0038 & 97.9816 \\
0.0189 & 0.0058 & 0.2071 & 0.0035 & 0.0058 & 0.0257 & 0.0088 & -0.0007 & 0.0001 & 0.0001 & 0.0036 & 97.9883 \\
\hline
\end{tabular}

Table 2. Chemical composition analysis of KS7 stainless steel.

\begin{tabular}{ccccccccccccc}
\hline Run & & $\mathrm{C}$ & \multicolumn{2}{c}{$\mathrm{Si}$} & $\mathrm{S}$ & $\mathrm{P}$ & $\mathrm{Mn}$ & & $\mathrm{Ni}$ & $\mathrm{Cr}$ \\
\hline 1 & & 0.1099 & 9.3663 & 0.0150 & 0.0640 & 10.0512 & & 0.3414 & 11.4664 \\
2 & & 0.1105 & 0.3534 & 0.0187 & 0.0728 & 10.6255 & 0.3532 & 11.1139 \\
$\mathrm{Avg}$ & & 0.1102 & 0.3598 & & 0.0169 & 0.0684 & & 10.7384 & & 0.3473 & & 11.292 \\
\hline Mo & $\mathrm{V}$ & $\mathrm{Cu}$ & $\mathrm{W}$ & $\mathrm{As}$ & $\mathrm{Sn}$ & $\mathrm{Co}$ & $\mathrm{Al}$ & $\mathrm{Pb}$ & $\mathrm{Ca}$ & $\mathrm{Zn}$ & $\mathrm{Fe} \%$ \\
\hline-0.3414 & 0.0748 & 4.6323 & 0.0817 & 0.0246 & 0.0219 & 0.0444 & 0.0146 & 0.0236 & 0.0004 & 0.0340 & 71.8657 \\
-0.0291 & 0.0731 & 4.0527 & 0.0800 & 0.0242 & 0.0229 & 0.0450 & 0.0121 & 0.0206 & 0.0003 & 0.0326 & 73.0176 \\
-0.0306 & 0.739 & 4.3425 & 0.0808 & 0.0244 & 0.0224 & 0.0447 & 0.0134 & 0.0221 & 0.0003 & 0.0333 & 72.4417 \\
\hline
\end{tabular}




\section{Results and Discussion}

\subsection{Results}

See Tables 1 and 2 and Figures 1 and 2.

\subsection{Discussion}

The corrosion characteristics of MCS and KS7 SS in 0.5 M, $100 \mathrm{ml} \mathrm{Nacl}$ solution is shown in Figure 1. MCS resumed the corrosion deterioration on the 6th day with CPR of 4.2 mpy and this trend continued throughout the 36 days of experimentation. It has the highest corrosion degradation between the 12th and 15th days with CPR of 7.8 mpy and 6.3 mpy. Whereas, KS7 SS experienced an approximate no corrosion deterioration within the first 9 days. A significant corrosion penetration was experienced between the 12th and 18th days as a result of sudden decrease of solution $\mathrm{pH}$ from 6.9 to $3.2,2.3$ and 2.2 on the 12th, 15th and 18th days respectively. The CPR recorded in these days is respectively $5.8 \mathrm{mpy}, 5.6 \mathrm{mpy}$ and 4.1 mpy. With increase in $\mathrm{pH}$ to 4.7 on the $21 \mathrm{st}$ day, there was a remarkably decrease to an approximate 0.0 mpy. This approximate no corrosion continued throughout the remaining period of 36 days experimentation. The formation of chromium oxide which acted as protective layer was responsible for this high passiveness to corrosion degradation of KS7 SS in this latter period. Comparatively, KS7 SS has moderate but better corrosion properties than MCS in saline medium. In similar manner, Figure 2 gives a description of the corrosion behaviour of MCS and KS7 SS in $0.5 \mathrm{M}, 100 \mathrm{ml} \mathrm{Na}_{2} \mathrm{CO}_{3}$ solution. MCS resumed corrosion degradation on the 6th day with CPR of 2.3 mpy. An inconsistent corrosion penetration was experienced from the 9th day till the 21 st day with peak value of 5.3 mpy. However, a daily gradual decrease of CPR began on the 24th day with CPR of 0.3 mpy. Between 33rd and 36th days, an approximate no corrosion deterioration was experienced. The formation of passive film at the latter part of experimentation was responsible for this unusual decrease in corrosion deterioration behaviour. Apart from the first 3 days when a CPR of 4.4 mpy was experienced, KS7 SS exhibited a very high corrosion resistance characteristic with an approximate CPR of 0.0 mpy throughout the 36 days. A protective barrier of Chromium oxide which was formed at the 6th day is undoubtedly the cause of KS7 SS corrosion passiveness in this carbonate environment. Observably, KS7 SS has exhibited a more reliable potential for corrosion resistance ability in sodium carbonate medium compared to MCS.

\section{Conclusions}

It is obvious from these experiments to draw the following conclusions:

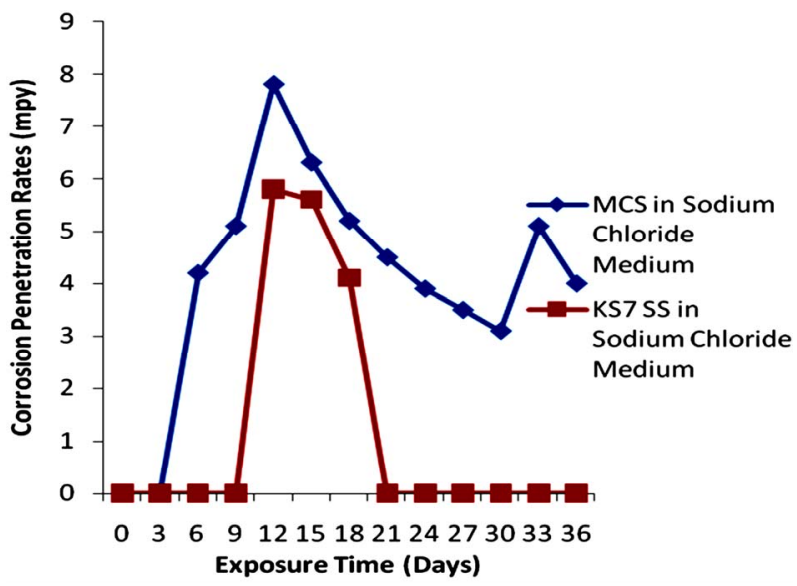

Figure 1. CPR of MCS and KS7 SS in NaCl solution.

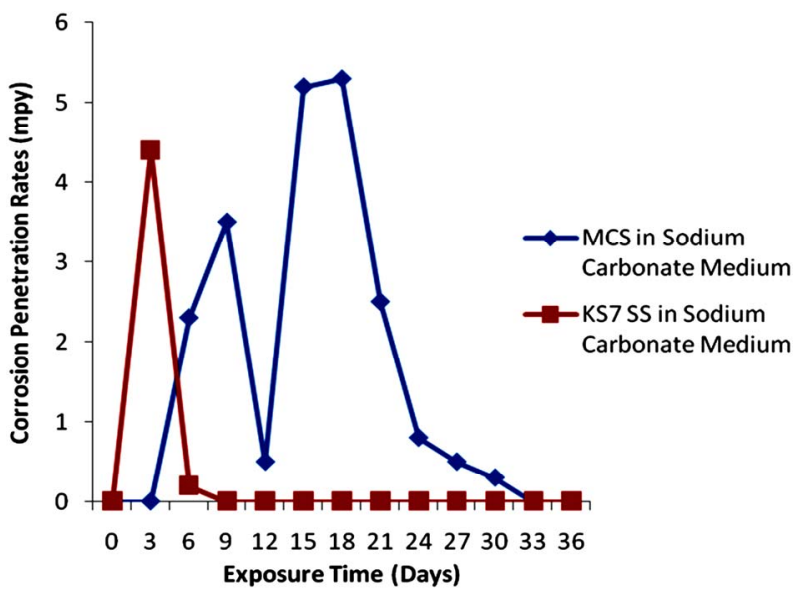

Figure 2. CPR of MCS and KS7 SS in $\mathrm{Na}_{2} \mathrm{CO}_{3}$.

1) Due to very high corrosion degradation characteristics of MCS, it is considered undependable and inappropriate alloy in the fabrication of equipments and tools for processing Salts and sodium carbonate (or where they exist as contaminants).

2) KS7 SS possess distinct corrosion resistance characteristics compared to MCS and consequently highly unfailing and acceptable alloy material for producing machinery, accessories, tanks , pipes and other engineering facilities meant to perform in sodium carbonate medium and moderately satisfactory in salty environment.

\section{REFERENCES}

[1] C. Berziou, K. Remy, A. Billard and J. Creus, "Corrosion Behaviour of dc Magnetron Sputtered $\mathrm{Fe}_{1-x} \mathrm{Mg}_{x}$ Alloy Films in $3 \mathrm{wt} \% \mathrm{NaCl}$ Solution," Corrosion Science, Vol. 49, No. 11, 2007, pp. 4276-4295. doi:10.1016/i.corsci.2007.04.008

[2] Q. I. Zhang, "Corrosion Assessment of Offshore Oil Pipeline Based on Ultrasonic Technique," Shanghai Jiao Tong University, Shanghai, 2008.

[3] D. T. Oloruntoba, O. O. Oluwole and O. Oguntade, "Com- 
parative Study of Corrosion Behaviour of Galvanized Steel and Coated Al 3103 Roofing Sheets in Carbonate and Chloride Environments," Materials \& Design, Vol. 30, No. 4, 2009, pp. 1371-1376.

[4] S. L. Jason, I. R. Richard, J. L. Edward, U. F. Alexander and J. L. Brenda, "An Evaluation of Carbon Steel Corrosion under Stagnant Seawater Conditions," Biofouling: The Journal of Bioadhesion and Biofilm Research, Vol. 20, No. 4-5, 2004, pp. 237-247.

[5] H. Möller, E. T. Boshoff and H. Froneman, "The Corrosion Behaviour of a Low Carbon Steel in Natural and Synthetic Seawaters," The Journal of The South African Institute of Mining and Metallurgy, Vol. 106, 2006, pp. 585-592.

[6] A. C. Ciubotariu, L. Benea and P. L. Bonora, "Corrosion Studies of Carbon Steel X60 by Electrochemical Methods," Journal of Optoelectronics and Advanced Materials, Vol. 12, No. 5, 2010, pp. 1170-1175.

[7] F. Deflorian, S. Rossi, B. Tancon and P. L. Bonora, "Corrosion Behaviour of Steel Ropes for Snow and Rockfall Barriers," Corrosion Engineering, Science and Technology, Vol. 39, No. 3, 2004, pp. 250-254.

\section{doi:10.1179/147842204X2853}

[8] J. Hu, D. A. Koleva, J. H. W. de Wit, H. Kolev and K. van Breugel, "Corrosion Performance of Carbon Steel in Simulated Pore Solution in the Presence of Micelles," Journal of the Electrochemical Society, Vol. 158, No. 3, 2011, pp. C76-C87.

[9] G. Elnura, "Comparison of Corrosion Resistance of 316 and Different Stainless Steel Grades," Master Thesis, University of Stavanger, Stavanger, 2011.

[10] A. Pfennig and A. Kranzmann, "Influence of $\mathrm{CO}_{2}$ on the Corrosion Behaviour of $13 \mathrm{Cr}$ Martensitic Stainless Steel AISI 420 and Low-Alloyed Steel AISI 4140 Exposed to Saline Aquifer Water Environment," Transactions of the Wessex Institute, 2006, $10 \mathrm{p}$.

[11] H. H. Uhlig and M. C. Morill, "Corrosion of 18-8 Stainless Steel in Sodium Chloride Solutions," Industrial \& Engineering Chemistry, Vol. 33, No. 7, 1941, pp. 875880 .

[12] J. Charles, J. D. Mithieux, J. Krautschick, N. Suutala, S. J. Antonio, S. Van Hecke and T. Pauly, "A New European 200 Series Standard to Substitute 304 Austenitics?" Revue de Métallurgie, Vol. 106, No. 2, 2009, pp. 90-98. 